\title{
Neighborhood Disadvantage and Telomere Length: Results from the Fragile Families Study
}

\author{
DOUGLAS S. MASSEY, BRANDON WAGNER, LOUIS DONNELLY, \\ SARA MCLANAHAN, JEANNE BROOKS-GUNN, IRWIN GARFINKEL, \\ COLTER MITCHELL, AND DANIEL A. NOTTERMAN
}

Telomeres are repetitive nucleotide sequences located at the ends of chromosomes that protect genetic material. We use data from the Fragile Families and Child Wellbeing Study to analyze the relationship between exposure to spatially concentrated disadvantage and telomere length for white and black mothers. We find that neighborhood disadvantage is associated with shorter telomere length for mothers of both races. This finding highlights a potential mechanism through which the unique spatially concentrated disadvantage faced by African Americans contributes to racial health disparities. We conclude that equalizing the health and socioeconomic status of black and white Americans will be very difficult without reducing levels of residential segregation in the United States.

Keywords: telomere, segregation, neighborhood disadvantage, concentrated poverty

In his seminal book, The Truly Disadvantaged, William Julius Wilson (1987) notes the growing concentration of poverty within black inner city neighborhoods and hypothesized that longterm exposure to spatially concentrated disadvantage was central to the perpetuation of poverty among African Americans. Since that time, a large body of research has sought to establish the existence of "neighborhood effects" on individual social, economic, and health outcomes. Although analyses of multilevel survey data and nonexperimental results derived from static group comparisons generally produced results consistent with Wilson's hypothesis (see Rubinowitz and Rosenbaum 2000; Sampson, Morenoff, and Gannon-Rowley 2002; Massey and Clampet-Lundquist 2008), experimental findings from the Moving to Opportunity (MTO) Study were initially less supportive (Kling, Lieberman, and Katz 2007).

The MTO study randomly assigned poor residents of public housing projects in five metropolitan areas to experimental and control groups. Members of the former group were of-

Douglas S. Massey is professor of sociology and public affairs at Princeton University. Brandon Wagner is assistant professor of sociology at Texas Tech University. Louis Donnelly is a postdoctoral research associate at Princeton University. Sara McLanahan is professor of sociology and public affairs at Princeton University. Jeanne Brooks-Gunn is professor of child development and education at Columbia University. Irwin Garfinkel is professor of contemporary urban problems at Columbia University. Colter Mitchell is research assistant professor at the University of Michigan. Daniel A. Notterman is lecturer with the rank of professor in molecular biology at Princeton University.

(C) 2018 Russell Sage Foundation. Massey, Douglas S., Brandon Wagner, Louis Donnelly, Sara McLanahan, Jeanne Brooks-Gunn, Irwin Garfinkel, Colter Mitchell, and Daniel A. Notterman. 2018. “Neighborhood Disadvantage and Telomere Length: Results from the Fragile Families Study." RSF: The Russell Sage Foundation Journal of the Social Sciences 4(4): 28-42. DOI: 10.7758/RSF.2018.4.4.02. Direct correspondence to: Douglas S. Massey at dmassey@princeton.edu, Office of Population Research, Wallace Hall, Princeton University, Princeton, NJ 08544.

Open Access Policy: RSF: The Russell Sage Foundation Journal of the Social Sciences is an open access journal. This article is published under a Creative Commons Attribution-NonCommercial-NoDerivs 3.0 Unported License. 
fered housing vouchers that required subjects to move into a low-poverty neighborhood and the latter received no offer of vouchers but continued to receive project-based assistance. Statistical comparisons of the two groups five to seven years after random assignment revealed that members of the experimental group did experience lower levels of neighborhood poverty and improved mental and physical health (Ludwig et al. 2011) but that the intervention offered "no convincing evidence of effects on educational performance; employment and earnings; or household income, food security, and self-sufficiency" (Orr et al. 2003, xv). These disappointing conclusions were generally sustained when the evaluation was repeated ten to fifteen years after random assignment (Sanbonmatsu et al. 2011).

More recently, however, the tide of evidence has begun to turn in favor of Wilson's "neighborhood effects" hypothesis. A quasiexperimental evaluation of a housing mobility project in New Jersey recently demonstrated that, when compared to members of a matched control group, adults who moved from a highto low-poverty residential environment experienced significantly lower exposure to disorder and violence, a lower frequency of negative life events, better mental health, higher employment rates, more earned income, and lower rates of welfare receipt (Massey et al. 2013). At the same time, adults who moved also became more involved in their children's academic development, and the children themselves evinced a dramatic increase in hours spent studying while gaining greater access to a quiet study space, higher quality schools, and lower levels of disorder and violence within schools, all of which allowed them to maintain strong grades despite attending more demanding schools (and hence receiving a much better education).

Using data from the Panel Study of Income Dynamics, Jeffrey Wodtke, David Harding, and Felix Elwert followed children from age one to seventeen and find that long-term exposure to concentrated neighborhood disadvantage sharply reduced the likelihood of high school graduation (2011), especially for children from low-income families (2016). Drawing on the same data source, Jonathan Rothwell and Douglas Massey show that, after adjusting for regional differences in purchasing power, lifetime household income would have been $\$ 910,000$ greater if people born into bottom-quartile of neighborhoods had instead been raised within a topquartile neighborhood, indicating a powerful neighborhood income effect that was two-thirds of the parental income effect (2014).

Finally, a recent reanalysis of the MTO subjects drawing on tax and census data from 2012 finds that children whose families moved into a low-poverty neighborhood before the age of thirteen by their mid-twenties earned annual incomes that were nearly $\$ 3,500$ greater than their counterparts in the control group (Chetty, Hendren, and Katz 2016). In addition, they displayed marriage rates that were two percentage points higher and attended college at rates that were 2.5 points greater. Children in the experimental group also attended higher quality colleges and universities.

At this point, a consensus seems to be emerging that neighborhoods do indeed matter across a variety of dimensions of human well-being (Massey 2013). Social scientists are consequently moving away from simple demonstrations of the existence of neighborhood effects and attempting to identify and model the specific mechanisms by which exposure to spatially concentrated disadvantage affects critical human outcomes (compare Sampson 2012; Sharkey 2013). In the current analysis, we focus on the relationship between neighborhood disadvantage and health, one of the earliest associations to emerge experimentally from the MTO study (Ludwig 2012). Rather than offering additional evidence simply to confirm the existence of such a relationship, however, we explore a potentially important pathway by which concentrated neighborhood disadvantage may get "under the skin" of people growing up and living in poor neighborhoods to create a potential biological precursor of elevated morbidity and mortality in later life.

\section{SOCIAL STRUCTURE,}

\section{STRESS, AND HEALTH}

We argue that one position within the social structure of society produces a high degree of exposure to spatially concentrated disadvantage. The social-structural position in question is defined by the intersection of high poverty 
and high residential segregation. The systematic residential segregation of any high-poverty group inevitably concentrates poverty spatially within neighborhoods inhabited by members of that group. Massey first identified this interaction using a simulation to show how rising rates of black poverty mechanically produced higher concentrations of black poverty as racial segregation increased, a relationship established empirically in subsequent research (Massey 1990; Massey and Eggers 1992; Massey and Fischer 2000). Although Massey's empirical confirmation of the segregation-poverty interaction was questioned on statistical grounds (Jargowsky 1997), the underlying mathematics of the interaction were later worked out and confirmed: "racial segregation and income segregation within race contribute importantly to poverty concentration, as Massey argued" (Quillian 2012, 354).

The group most subject to this interaction is African Americans, who in many metropolitan areas are simultaneously the poorest and most segregated minority group. These circumstances expose them to uniquely high concentrations of neighborhood disadvantage compared with other racial-ethnic groups (Massey and Rugh forthcoming). This fact is important because, as Robert Sampson points out, when it comes to urban ecology "things go together" (2012). Areas of spatially concentrated disadvantage also tend to be areas of high crime, elevated violence, excessive mortality, low collective efficacy, fragmented social ties, and limited capacity for collective action. It is hardly surprising, therefore, that neighborhood disadvantage has been identified as the critical nexus for the intergenerational transmission of poverty among African Americans (Sharkey 2013).

Previous work has found that neighborhood disadvantage is associated with biological markers linked to stress or health, including cortisol levels and C-protein reactivity (Rudolph et al. 2014; Hackman et al. 2012; Karb et al. 2012), blood pressure (Cathorall et al. 2015), DNA methylation (King et al. 2016), and summative measures such as allostatic load (Gustafsson et al. 2014; Finch et al. 2010). In this article, we conceptualize the attenuation of telomere length as a potential mechanism by which exposure to neighborhood disadvantage undermines health in later life. Telomeres are repetitive nucleotide sequences located at the ends of human chromosomes, which act as buffers to protect genetic material from deterioration and errant recombination during cell division (Blackburn 2006; Kipling 1995).

Telomeres naturally shorten in the course of human aging (Wilhide 2014). The normal process of shortening over time can be accelerated by exposure to environmental stressors, however (Sapolsky 2004). Despite some evidence of positive publication bias, metaanalyses provide support for the association between perceived stress and telomere length (Schutte and Malouf 2014; Mathur et al. 2016). These results support the conclusion of Elissa Epel and her colleagues that "stress ... is significantly associated with higher oxidative stress, lower telomerase activity, and shorter telomere length" $(2004,17312)$.

We hypothesize that one critical source of environmental stress for African Americans is their elevated exposure to spatially concentrated disadvantage, thus yielding a potential biosocial pathway connecting their position in the U.S. social structure to health. Specifically, the combination of high poverty and high segregation uniquely expose African Americans to spatially concentrated disadvantage, yielding a prolonged exposure to stress, which functions over time to shorten telomeres of African Americans prematurely, with potential adverse health consequences later in life.

Admittedly, the nature of the relationship between shortened telomeres and poor health is not settled. Some scholars have argued that the poor prediction of mortality risk (Glei et al. 2016) and physical decline (Harris et al. 2016) by telomere length, particularly in the oldestold (Yu et al. 2015; Martin-Ruiz et al. 2005), implies that telomere length is a "weak biomarker [of human aging] with poor predictive accuracy compared with many traditional covariates" (Sanders and Newman 2013). However, numerous other studies document associations between telomere length and a variety of subsequent health outcomes, including all-cause mortality risk, infectious disease mortality, coronary heart disease, stroke, myocardial infarction, diabetes, cancer incidence, and cancer mortality (Glei et al. 2016; see also Marioni et 
al. 2016; Fitzpatrick et al. 2011; Haycock et al. 2014; Goglin et al. 2016; D'Mello et al. 2014; Willeit, Willeit, and Mayr 2010).

Though the exact mechanisms that link telomere length to subsequent health is unclear, a recent review highlights a variety of potential mechanisms by which telomere length might influence health, concluding that "telomere attrition can lead to potentially maladaptive cellular changes, block cell division, and interfere with tissue replacement," and that "greater overall telomere attrition predicts mortality and age-related diseases" (Blackburn, Epel, and Lin 2015, 1193). Such a link between stressful social environments and compromised health has long been hypothesized, that persistent exposure to disadvantaged circumstances contributes to a process of human "weathering" in which disadvantaged populations age prematurely from high levels of stress and consequently experience poorer health as the life course proceeds (Geronimus 1992; see also DiPrete and Eirich 2006; Geronimus et al. 2006; Walsemann, Gee, and Geronimus 2009).

We argue here that a key source of stress for African Americans, beyond whatever instances of exclusion and discrimination they may experience while navigating U.S. society, is their long-term exposure to high spatial concentrations of disadvantage, which potentially contribute to weathering at the cellular level in the form of shortened telomeres (Epel et al. 2004; Sapolsky 2004). Because racial gaps in health and mortality typically are not eliminated by controlling for socioeconomic status and demographic factors, we argue that racial differences in exposure to concentrated disadvantage carry considerable potential to account more fully for black shortfalls in health (see Kitagawa and Hauser 1973; Geruso 2012).

One potential mechanism is the pathway hypothesized here, in which high levels of segregation and poverty interact to concentrate poverty within black neighborhoods, which in turn exposes African Americans to high concentrations of neighborhood disadvantage, which ultimately shortens black telomere lengths to foretell an elevated risk of health problems over the life course. The connection between segregation, poverty, and neighborhood disadvantage is well established (Quil- lian 2012) and evidence of a link between telomere length and poor health is rapidly accumulating (see Blackburn, Epel, and Lin 2015). Here we seek to demonstrate an association between concentrated neighborhood disadvantage and telomere length in a large nationally representative sample.

Prior work offers suggestive evidence of such a link. Katherine Theall and her colleagues, for example, gathered data from children in New Orleans and show that exposure to neighborhood disorder and poverty was associated with shorter telomeres (2013). Using a sample of adults from locations around the United States, Belinda Needham and her colleagues also find a strong negative relationship between telomere length and the quality of the neighborhood environment, as measured by aesthetics, safety, and social cohesion (2015). Likewise, Minjung Park and her colleagues used data from a longitudinal survey of Dutch adults to demonstrate that telomere length varied inversely with neighborhood quality, as measured by selfreported disorder, crime, and noise (2015).

Recently Arline Geronimus and her colleagues compiled a sample of respondents from three Detroit neighborhoods and find that respondents who were most satisfied with their neighborhood circumstances displayed significantly longer telomeres than others. Using data from the Fragile Families and Child Wellbeing Study, Colter Mitchell and his colleagues demonstrate that black boys who experienced disadvantaged home environments displayed significantly shorter telomeres by age nine than statistically similar boys who grew up in advantaged environments (2014). Likewise, Stacy Drury and her colleagues find that telomeres were significantly shorter among children who reported greater exposure to family violence and disruption (2014). Irdan Shalev and his colleagues discovered that children exposed to multiple sources of violence and mistreatment while growing up displayed significantly more telomere shrinkage between ages five and ten than other children (2013).

\section{DATA AND METHODS}

Our data come from the Fragile Families and Child Wellbeing Study, which is based on a stratified, multistage, probability sample of children 
born in large U.S. cities between 1998 and 2000. Around three-quarters of the births were to unmarried mothers (hence yielding "fragile" families). Baseline interviews were conducted with mothers in the hospital soon after the child's birth, and fathers were interviewed in the hospital or by phone. Follow-up interviews were conducted with both parents when the child was one, three, five, and nine years old. About nine years after the birth of their child, 2,667 mothers provided saliva samples to enable biological assays of telomere length.

Telomere length was assessed using a quantitative real-time polymerase chain reaction (PCR) assay that yielded absolute measurements in numbers of kilobases. To guard against overly influential outlier cases, we eliminated respondents with telomere lengths below the 1st percentile or above the 99th percentile of the distribution and to facilitate analysis and we took the natural log of telomere length as our dependent variable in a simple linear model (see Mitchell et al. 2014). Most research on telomeres to date has relied on peripheral blood mononuclear cells from whole blood as a source of DNA. To consider the relationship between DNA from blood and that derived from saliva, Mitchell and colleagues asked sixteen healthy adult volunteers (ten females and six males) to contribute both blood and saliva samples (2014).

After discarding a single outlier (by four standard deviations) from one of the blood samples, they find that telomere length was greater in the saliva samples but nonetheless highly correlated with telomere length in the blood samples. This difference is not surprising since different cell types have different rates of division and thus different rates of telomere attrition. Because the saliva- and blood-based telomere lengths were highly correlated with one another, Mitchell and colleagues conclude there was no a priori reason to prefer one source over the other and proceeded with their analysis of telomere lengths derived from the Fragile Families data.

Our principal independent variable is an index of neighborhood disadvantage developed by Wodtke, Harding, and Elwert (2011). This measure is created from a principal component analysis of tract-level items that included rates of poverty, unemployment, female headedness, and welfare receipt, along with the percentages of persons age twenty-five and older who lacked a high school diploma, held a college degree, and occupied a managerial or professional occupation. We measured neighborhood disadvantage cumulatively from the first to the fifth wave of the survey using census tract records from the 2000 Census and the 2005-2009 American Community Survey (ACS), linking them to geocoded individual records for mothers and children. For the 2000 values and the few cases dating to 1998 or 1999 , we used 2000 census estimates; for the 2007 and 2008 values, we used the ACS 2005-2009 estimates; and for years between, we interpolated.

To make sure that we were not capturing overall changes in tract values (stemming from nationwide events such as the Great Recession), we standardized all values within years across the national sample of census tracts. To incorporate the effects of moves between neighborhoods during the period of observation, we merged tract data from the census and the ACS; for individuals who changed tracts between waves, we set the midpoint between the two data collection dates as the year in which they moved. All models were estimated in Stata 14 and controlled as appropriate for indicators of demographic characteristics, educational attainment, living arrangements, and socioeconomic status.

Table 1 presents means for each independent variable by race-ethnicity for mothers at the time of the age-nine survey. The huge differential in exposure to cumulative neighborhood disadvantage between whites and blacks is immediately apparent in the first line of the table. Whereas the Wodtke index of neighborhood disadvantage stood at -0.252 for white mothers, the factor score for black mothers was 1.198. The mean age of mothers at the time of telomere collection was 33.4 years for blacks, and 36.4 years for whites, and the percentage foreign born was around 3 percent for whites and blacks. Black mothers displayed higher body mass indices (ratio of weight to height squared) than their white counterparts, with BMI Z-scores of 0.161 and -0.261 respectively. The average number of moves made before the child reached age nine differed slightly by race, with the number being 3.1 for blacks and 2.7 for whites.

As one might expect, education levels dif- 
Table 1. Means of Variables in Analysis of Neighborhood Disadvantage and

Telomere Length

\begin{tabular}{|c|c|c|c|}
\hline Variable & Total & Whites & Blacks \\
\hline \multicolumn{4}{|c|}{ Neighborhood disadvantage } \\
\hline Wodtke index & 0.760 & -0.252 & 1.198 \\
\hline \multicolumn{4}{|l|}{ Telomere length } \\
\hline Logged kilobases & 1.839 & 1.801 & 1.855 \\
\hline \multicolumn{4}{|l|}{ Mother's characteristics } \\
\hline Age at TL collection & 34.326 & 36.407 & 33.424 \\
\hline Foreign born & 0.030 & 0.028 & 0.031 \\
\hline Body mass (Z-score) & 0.034 & -0.261 & 0.161 \\
\hline Moves during study & 2.997 & 2.679 & 3.136 \\
\hline \multicolumn{4}{|l|}{ Education at birth of child } \\
\hline Less than high school & 0.279 & 0.168 & 0.328 \\
\hline High school & 0.329 & 0.249 & 0.363 \\
\hline Some college & 0.271 & 0.281 & 0.266 \\
\hline College or more & 0.121 & 0.302 & 0.043 \\
\hline \multicolumn{4}{|c|}{$\begin{array}{l}\text { Mother-father relationship } \\
\text { at birth }\end{array}$} \\
\hline Married & 0.238 & 0.509 & 0.120 \\
\hline Cohabiting & 0.335 & 0.301 & 0.349 \\
\hline Other & 0.427 & 0.189 & 0.531 \\
\hline \multicolumn{4}{|l|}{ Household SES at birth } \\
\hline Household poverty ratio & 2.431 & 4.060 & 1.726 \\
\hline Household welfare & 0.379 & 0.213 & 0.450 \\
\hline Number of cases & 1,661 & 502 & 1,159 \\
\hline
\end{tabular}

Source: Authors' compilation of data from the Fragile Families and Child Wellbeing Survey.

fered by race. Whereas 33 percent of black respondents had less than a high school education, only 17 percent of white respondents did. Likewise, 30 percent of whites but only 4 percent of blacks were college graduates. A similar contrast was observed for the mothers' family situation at the time of the birth. Just 12 percent of black mothers were married and 35 percent were cohabiting, versus 50 percent and 31 percent of whites. In other words, nearly 80 percent of white mothers but only 47 percent of black mothers were married or cohabiting at the time of birth. As with mother's education, household income was greater for whites than for blacks. The income-topoverty ratio was 4.1 for white and 1.7 for blacks. As one would expect given these income figures, the percentage on welfare for black mothers was double that of white moth- ers, with figures of 45 percent and 21 percent respectively.

TELOMERES, SOCIOECONOMIC STATUS, AND NEIGHBORHOOD DISADVANTAGE To set the stage for our multivariate analysis, we offer a simple description of intergroup differences in telomere length (TL), socioeconomic status, and neighborhood disadvantage. As table 1 shows, we observe clear differences in TL between whites and blacks. White mothers clearly stand out for their low values, averaging 1.801 kilobases to 1.855 for blacks, a statistically significant difference. To understand the distribution of telomere length, figure 1 plots mothers' telomere length (in logged kilobases) by race. Though they have a similar range of values, it is clear from this histogram that the distribution of telomere length is dis- 
Figure 1. Density Distribution, Telomere Length
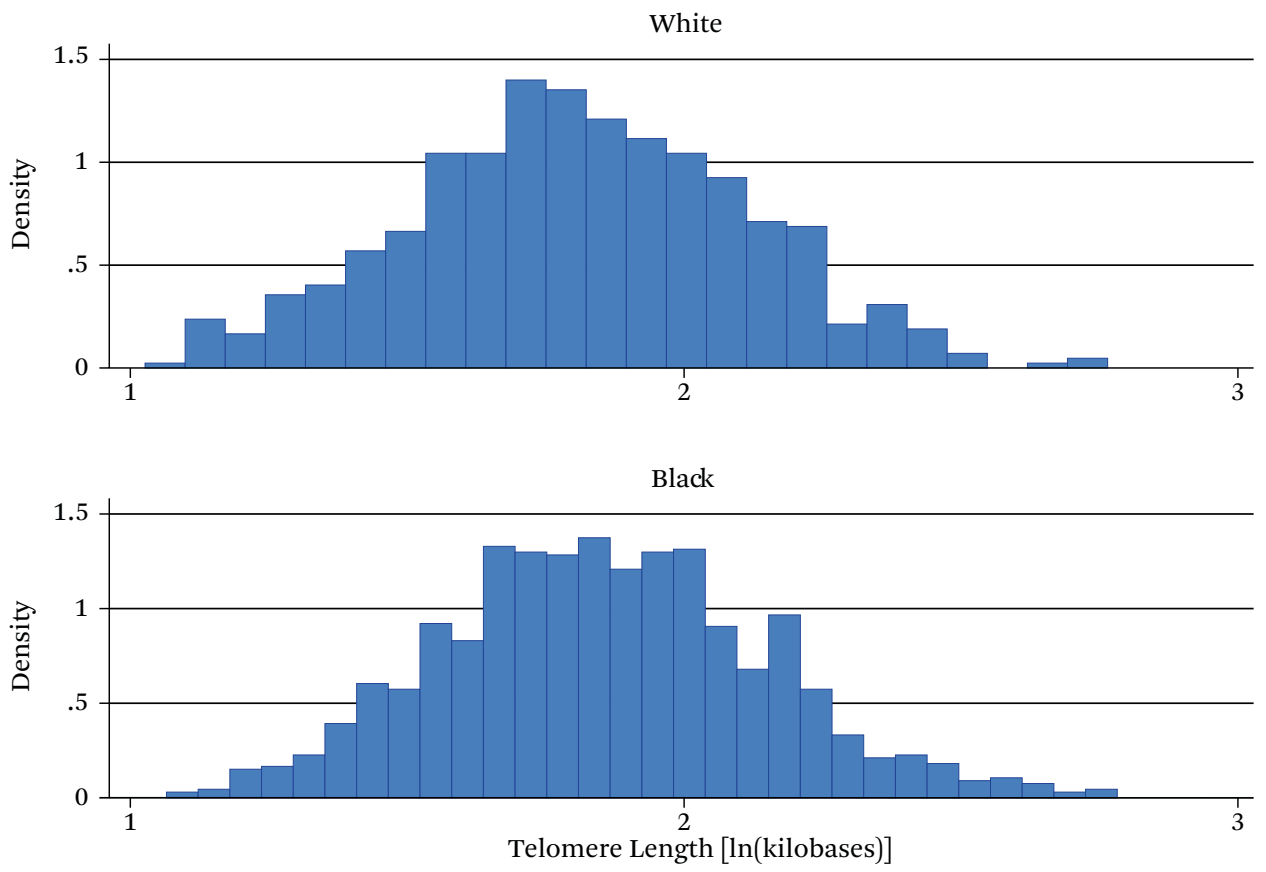

Source: Authors' compilation of data from the Fragile Families and Child Wellbeing Survey.

tributed more to the right for blacks relative to whites. It may seem surprising that black mothers have longer telomeres than white mothers given their greater exposure to disadvantage, but other researchers have noted similar blackwhite differentials over the life course (Needham et al. 2015; Brown et al. 2016; Hansen et al. 2016; Lynch et al. 2016; Drury et al. 2014; Hunt et al. 2008). Understanding the reasons for this racial differential in telomere length remains an important task for future research.

Whatever the baseline telomere length, what we are trying to test here is whether exposure to a stressor "speeds up" the rate at which telomeres attrite-that is, whether it affects the net difference between rates of telomere loss and synthesis. Thus we set aside any investigation of racial differences in baseline TL and focus simply on whether exposure to neighborhood disadvantage is indeed associated with shorter telomeres and whether the strength of this association differs between blacks and whites. Though the Fragile Families data limit us to a single measurement of telomere length and cannot sustain attributions of causality, observed point-in-time differences by neighborhood disadvantage nonetheless provide suggestive evidence of telomere attrition.

Besides neighborhood disadvantage, family deprivation might also influence telomere length and thus is important also to consider. Figure 2 calibrates the potential for intergroup differences in household income to shorten telomeres by showing the distribution of income-to-poverty ratios for respondents by race. In both cases, these ratios concentrate at values below 5.0; and as one might expect, values for blacks are skewed much more toward the low end of the scale and whites more toward the upper end. In addition, whereas black mothers display virtually no income-to-poverty ratios above 5.0, such values are frequent among white mothers. Thus, income differences are also likely to be associated with shorter TL and need to be controlled in statistical models.

However, the black-white differential in household income is not nearly as extreme as the racial differential in neighborhood income, as shown in figure 3, which presents distributions of the Wodtke neighborhood disadvantage index for white and black mothers. 
Figure 2. Density Distribution, Income to Poverty Ratio

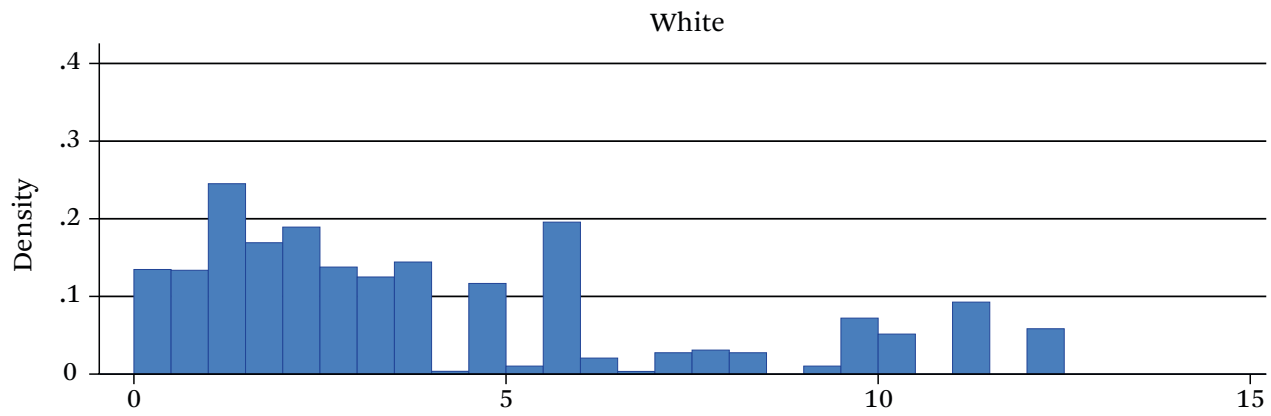

Black

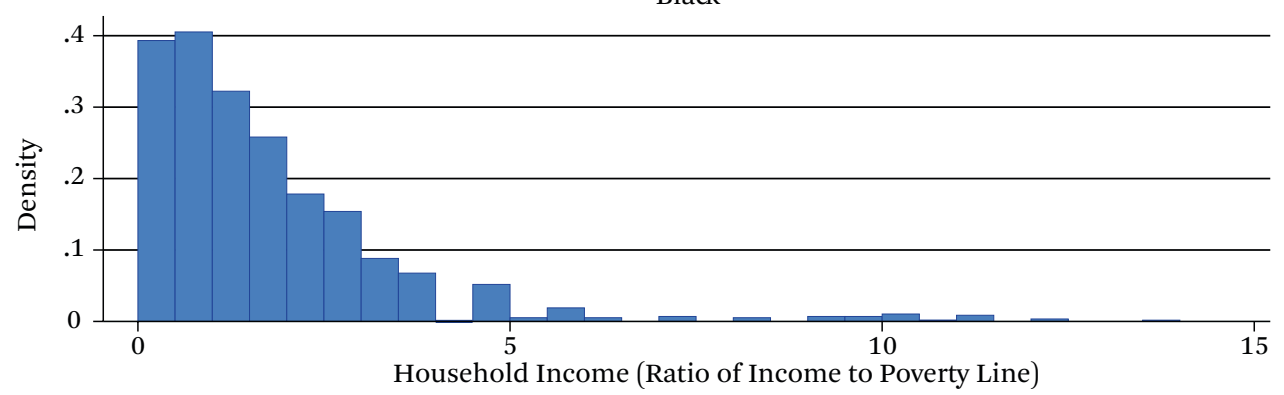

Source: Authors' compilation of data from the Fragile Families and Child Wellbeing Survey.

Figure 3. Density Distribution, Wodtke Index
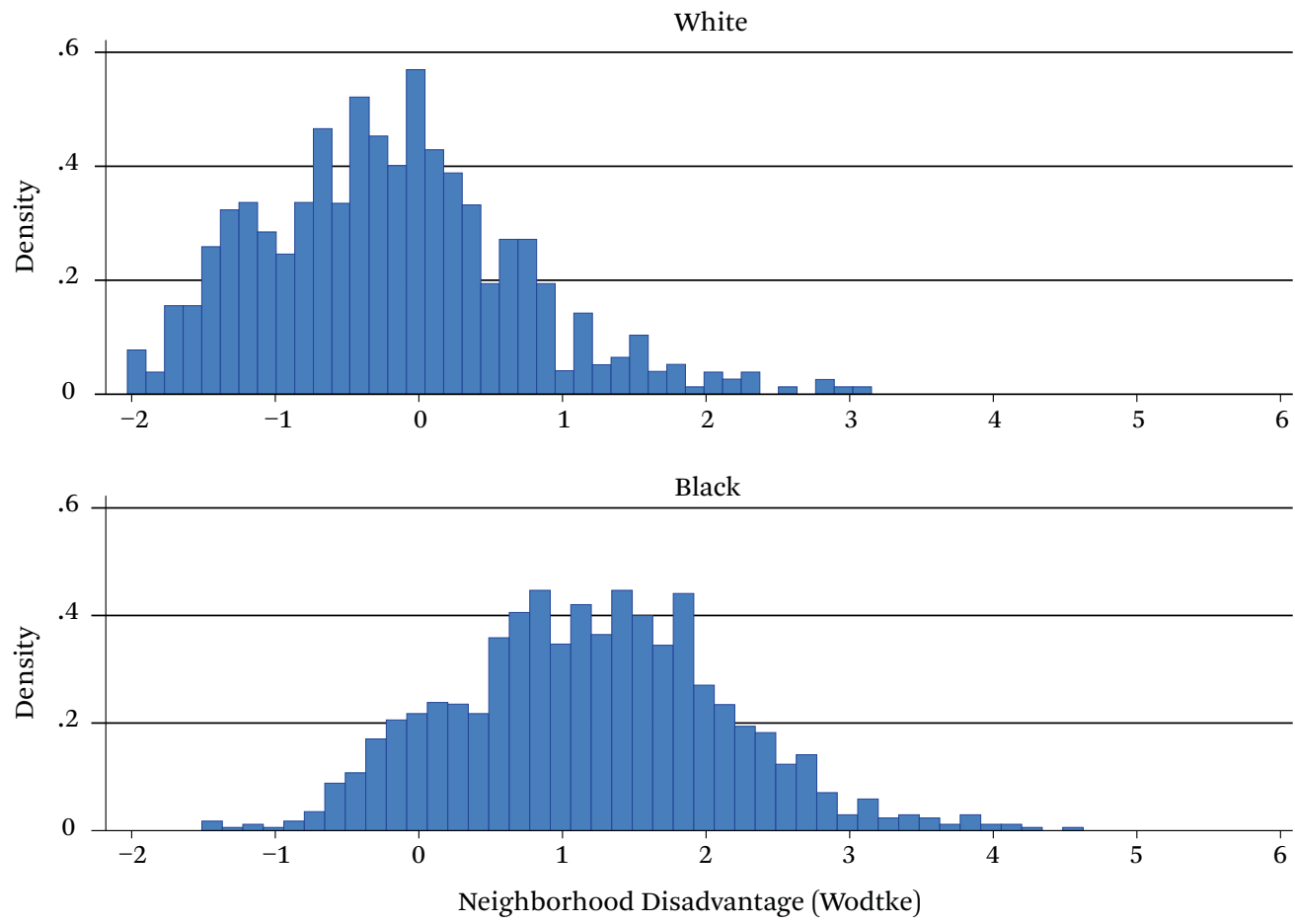

Source: Authors' compilation of data from the Fragile Families and Child Wellbeing Survey. 
Table 2. OLS Regression, Effect of Neighborhood Disadvantage

\begin{tabular}{|c|c|c|c|c|}
\hline \multirow[b]{2}{*}{ Independent Variables } & \multicolumn{2}{|c|}{$\begin{array}{l}\text { Controlling for } \\
\text { Social Background }\end{array}$} & \multicolumn{2}{|c|}{$\begin{array}{c}\text { Controlling for } \\
\text { Social Background and } \\
\text { Neighborhood Disadvantage }\end{array}$} \\
\hline & $\mathrm{B}$ & SE & B & SE \\
\hline \multicolumn{5}{|l|}{ Mother's race-ethnicity } \\
\hline White & - & - & - & - \\
\hline Black & $0.052^{* *}$ & 0.018 & $0.074^{* * *}$ & 0.020 \\
\hline \multicolumn{5}{|l|}{ Neighborhood disadvantage } \\
\hline Wodtke index & - & - & $-0.023^{*}$ & 0.009 \\
\hline \multicolumn{5}{|l|}{ Mother's characteristics } \\
\hline Age at telomere collection & $-0.003^{+}$ & 0.001 & $-0.003^{+}$ & 0.001 \\
\hline Foreign born & 0.041 & 0.043 & 0.032 & 0.043 \\
\hline Body mass index & -0.001 & 0.008 & 0.004 & 0.008 \\
\hline Moves during study & 0.000 & 0.003 & -0.001 & 0.003 \\
\hline \multicolumn{5}{|l|}{ Mother's education at birth } \\
\hline Less than high school & - & - & - & - \\
\hline High school & 0.015 & 0.019 & 0.009 & 0.019 \\
\hline Some college & $0.043^{*}$ & 0.021 & 0.032 & 0.021 \\
\hline College or more & 0.024 & 0.034 & 0.006 & 0.035 \\
\hline \multicolumn{5}{|l|}{$\begin{array}{l}\text { Mother-father relationship } \\
\text { at birth }\end{array}$} \\
\hline Married & - & - & - & - \\
\hline Cohabiting & 0.028 & 0.024 & 0.031 & 0.024 \\
\hline Other & 0.025 & 0.025 & 0.028 & 0.025 \\
\hline \multicolumn{5}{|l|}{ Mother's SES at birth } \\
\hline Household poverty ratio & 0.003 & 0.004 & 0.001 & 0.004 \\
\hline Household welfare use & -0.008 & 0.017 & -0.005 & 0.017 \\
\hline Constant & $1.847^{* * *}$ & 0.061 & $1.859^{* * *}$ & 0.061 \\
\hline $\mathrm{R}^{2}$ & 0.008 & & 0.010 & \\
\hline Number of cases & 1,661 & & 1,661 & \\
\hline
\end{tabular}

Source: Authors' compilation of data from the Fragile Families and Child Wellbeing Survey. ${ }^{+} p<.1 ;{ }^{*} p<.05 ;{ }^{* *} p<.01 ;{ }^{* * *} p<.001$

Whereas neighborhood disadvantage indices for the vast majority of white mothers lie between -1.0 and +1.0 , indicating low to moderate levels of neighborhood disadvantage, the vast majority of black mothers display indices that are above 1.0, most falling in the range from 1.0 to 4.0 but with some values of 5.0 or greater, index values that are almost never observed for whites. Thus the racial contrast is much greater with respect to neighborhood socioeconomic status than household socioeconomic status.

\section{EFFECTS OF NEIGHBORHOOD}

\section{DISADVANTAGE ON TELOMERE LENGTH}

Table 2 presents two ordinary least squares (OLS) regression models estimated to predict the natural log of telomere length for black and white mothers in the Fragile Families dataset. The left-hand model includes dummy variables for group membership and indicators of the mother's demographics, education, relationship with the father, and socioeconomic status at the time of the child's birth. The right-hand 
equation contains the same independent variables with the addition of the Wodtke Index of neighborhood disadvantage. Looking at the left-hand columns we see that in the absence of a control for neighborhood disadvantage the average TL for black mothers remains significantly greater than that of white mothers $(p<$ .01 ), consistent with the data shown in figure 1. In addition, with the notable exception of having some college education, socioeconomic status does not seem to play a significant role in determining TL among respondents, a finding that was robust across different model specifications we considered.

The right-hand equation adds in neighborhood disadvantage, which is significantly associated with shorter TL $(p<.05)$. According to the estimated model, each point increase in the index of neighborhood disadvantage is associated with a decline of 0.023 logarithmic points of TL. Including neighborhood disadvantage in the model slightly increases the black-white gap in TL, though the shift is not significant. Although this model estimates a single coefficient for neighborhood disadvantage, we might anticipate that whites and blacks experience neighborhood disadvantage differently. To test this possibility, we estimated an additional model with an interaction term that allowed the effect of neighborhood disadvantage to vary between races but we did not find a significant interaction. We came to the same conclusion when we estimated the entire model separately for black and white mothers and found the coefficients for neighborhood disadvantage not to be statistically different in the black and white models.

Thus neighborhood disadvantage appears to operate similarly with regard to telomere length across the races. The Fragile Families data, however, only contain information on neighborhood disadvantage for the nine years of women's lives subsequent to the baseline interview. Our analysis thus ignores whatever neighborhood circumstances women experienced before the survey date, around twothirds of their lifetimes. Although we do not have information on the specific tract of residence for this period, in additional models not shown we use fixed effects to account for the city of residence at the time of the baseline sur- vey and found that findings were robust to the inclusion of these city-level controls.

\section{CONCLUSION AND IMPLICATIONS}

Research clearly establishes that segregation and poverty interact to concentrate poverty spatially. The residential segregation of any group with a high rate of poverty inevitably concentrates poverty at high levels within neighborhoods inhabited by that group. Studies also identify telomeres (nucleotide sequences located at the ends of chromosomes) as critical buffers that protect genetic material from deterioration during cell division and that telomeres naturally shorten with age to foretell senescence. However, research also reveals that long-term exposure to high levels of stress can shorten human telomeres prematurely, potentially increasing later risks of morbidity and mortality.

In the current analysis, we hypothesized that prolonged exposure to spatially concentrated disadvantage constitutes a key source of stress for African Americans and thus may help to explain persistent racial differentials in health and life expectancy that do not disappear when socioeconomic status is controlled. To support this hypothesis we used multilevel data from the Fragile Families and Child Wellbeing Study and, using an index developed by Wodtke and colleagues (2011), we documented the distinctively high concentrations of neighborhood disadvantage experienced by African Americans relative to whites and confirmed that black inequality with respect to neighborhood disadvantage far exceeds that with respect to household income.

We went on to estimate regression models that predicted telomere length while controlling for other socioeconomic and demographic characteristics. We find the Wodtke index to be a significant predictor of telomere length among both blacks and whites. Subsequent investigations reveal no significant difference between blacks and whites in the extent to which exposure to neighborhood disadvantage was associated with shorter TL. Blacks are simply exposed to far more neighborhood disadvantage than whites, thus predicting greater shortening from their baseline TL. The difference in average neighborhood disadvantage 
among white and black respondents (Wodtke index $=-0.252$ and 1.198 , respectively) implies a predicted difference in telomere length of 0.04 logarithmic points. Thus an African American respondent living in an average black neighborhood would be expected to have telomeres 0.04 logarithmic points shorter than those of an identical respondent living in an average white neighborhood. Conversely, an average white respondent living in an average white neighborhood would be expected to have telomeres 0.04 logarithmic points longer than those of an identical respondent living in an average black neighborhood. Though our results rely on cross-sectional comparisons of telomere length and cannot be taken as causal, they do provide suggestive evidence that the prolonged exposure to spatially concentrated disadvantaged experienced by African Americans is associated with greater telomere attrition.

In relying on between-person comparisons of telomere length, this study faces two major challenges future work should seek to address. First, as with all cross-sectional data analyses, correlations with omitted variables threaten between-person comparisons of telomere length. Though we included a variety of potentially relevant controls, the use of crosssectional comparisons precludes us from asserting a causal relationship between neighborhood disadvantage and telomere length. Second, the proposed theoretical model with telomeres as a mechanism linking neighborhood disadvantage to later-life health outcomes is primarily motivated by work on the health consequences of telomere attrition (that is, change in telomere length over time). However, we are unable to measure the actual process of telomere attrition with a single time point of data available. Though differences in length could imply differences in telomere attrition, they also capture mean differences between groups. The measurement of telomeres at multiple time points is becoming more common in datasets, including future waves of the Fragile Families Study itself. As these data become available, researchers should seek to determine whether differences in exposure to neighborhood disadvantage are diachronically associated with actual telomere attrition and not just associated with cross-sectional TL disparities at a point in time.

Although our results are necessarily preliminary and await replication by other researchers using other datasets, they nonetheless add to a growing body of work demonstrating how inequality can be perpetuated through the nexus of neighborhood disadvantage, and potentially through biological as well as social mechanisms. Given the salient role of neighborhoods in perpetuating poverty over the life course and across generations, the research presented here suggests that improvements in black education and income alone may not be enough to eliminate racial differentials in health and socioeconomic status as long as residential segregation remains a characteristic structural feature of American society. Moving toward a more just and equal society requires not simply reducing discrimination in the social and economic spheres, but equalizing opportunities in the residential sphere as well. As of 2010, more than half of blacks inhabiting U.S. metropolitan areas remained highly segregated and one-third were hypersegregated (Massey and Tannen 2015). As long as such conditions continue to prevail, segregation will continue to serve as the linchpin of racial stratification in the United States (Pettigrew 1979).

\section{REFERENCES}

Blackburn, Elizabeth H., ed. 2006. Telomeres. Cold Spring Harbor, N.Y.: Cold Spring Harbor Monograph Series.

Blackburn, Elizabeth H., Elissa S. Epel, and Jue Lin. 2015. “Human Telomere Biology: A Contributory and Interactive Factor in Aging, Disease Risks, and Protection." Science 350(6265): 1103-98.

Brown, Lauren, Belinda Needham, and Jennifer Ailshire. 2016. “Telomere Length Among Older U.S. Adults: Differences by Race/Ethnicity, Gender, and Age." Journal of Aging and Health (July 27): 1-7. DOI: 10.1177/089826431666139.

Cathorall, Michelle L., Huaibo Xin, Andrew Peachy, Daniel L. Bibeau, Mark Schulz, and Robert Aronson. 2015. "Neighborhood Disadvantage and Variations in Blood Pressure." American Journal of Health Education 46(5): 266-73.

Chetty, Raj, Nathaniel Hendren, and Lawrence F. Katz. 2016. “The Effects of Exposure to Better Neighborhoods on Children: New Evidence from 
the Moving to Opportunity Experiment." American Economic Review 106(4): 855-902.

D'Mello, Matthew J. J., Stephanie A. Ross, Matthias Briel, Sonia S. Anand, Hertzel Gerstein, and Guillaume Pare. 2014. "The Association Between Shortened Leukocyte Telomere Length and Cardio-Metabolic Outcomes: A Systematic Review and Meta-Analysis." Cardiovascular Genetics (November 18). DOI: 10.1161/CIRCGENETICS .113 .000485 .

DiPrete, Thomas A., and Gregory A. Eirich. 2006. “Cumulative Advantage as a Mechanism for Inequality: A Review of Theoretical and Empirical Developments." Annual Review of Sociology 32(1): 271-97.

Drury, Stacy S., Emily Mabile, Zoë H. Brett, Kyle Esteves, Edward Jones, Elizabeth A. Shirtcliff, and Katherine P. Theall. 2014. "The Association of Telomere Length with Family Violence and Disruption." Pediatrics 134(1): e128-37.

Epel, Elissa S., Elizabeth H. Blackburn, Jue Lin, Firdaus S. Dhabhar, Nancy E. Adler, Jason D. Morrow, and Richard M. Cawthon. 2004. “Accelerated Telomere Shortening in Response to Life Stress." Proceedings of the National Academy of Sciences 101(49): 17312-15.

Finch, Brian K., D. Phuong Do, Melonie Heron, Chloe Bird, Teresa Seeman, and Nicole Lurie. 2010. “Neighborhood Effects on Health: Concentrated Advantage and Disadvantage." Health and Place 16(5): 1058-60.

Fitzpatrick, Annette L., Richard A. Kronmal, Masayuki Kimura, Jeffrey P. Gardner, Bruce M. Psaty, Nancy S. Jenny, Russell P. Tracy, Sheetal Hardikar, and Abraham Aviv. 2011. "Leukocyte Telomere Length and Mortality in the Cardiovascular Health Study." Journals of Gerontology: Series $A$ 66A(4): 421-29.

Geronimus, Arline T. 1992. "The Weathering Hypothesis and the Health of African American Women and Infants." Ethnicity and Disease 2(3): 207-21.

Geronimus, Arline T., Margaret Hicken, Danya Keene, and John Bound. 2006. "'Weathering' and Age Patterns of Allostatic Load Scores Among Blacks and Whites in the United States." American Journal of Public Health 96(5): 826-33.

Geronimus, Arline T., Jay A. Pearson, Erin Linnenbringer, Amy J. Schulz, Angela G. Reyes, Elissa S. Epel, Jue Lin, and Elizabeth H. Blackburn. 2015. “Race-Ethnicity, Poverty, Urban Stressors, and Telomere Length in a Detroit Community-Based
Sample." Journal of Health and Social Behavior (April 30). DOI: 10.1177/0022146515582100.

Geruso, Michael. 2012. “Black-White Disparities in Life Expectancy: How Much Can the Standard SES Variables Explain?" Demography 49(2): 553-74.

Glei, Dana A., Noreen Goldman, Rosa Ana Risques, David H. Rehkopf, William H. Dow, Luis RoseroBixby, and Maxine Weinstein. 2016. "Predicting Survival from Telomere Length Versus Conventional Predictors: A Multinational PopulationBased Cohort Study." PloS One 11(4): e0152486.

Goglin, Sarah E., Ramin Farzaneh-Far, Elissa S. Epel, Jue Lin, Elizabeth H. Blackburn, and Mary A. Whooley. 2016. "Change in Leukocyte Telomere Length Predicts Mortality in Patients with Stable Coronary Heart Disease from the Heart and Soul Study." PLoS One 11(12): e0168868.

Gustafsson, Per E., Miguel San Sebastian, Urban Janlert, Töres Theorell, Hugo Westerlund, and Anne Hammarström. 2014. “Life-Course Accumulation of Neighborhood Disadvantage and Allostatic Load: Empirical Integration of Three Social Determinants of Health Frameworks." American Journal of Public Health 104(5): 904-10. Hackman, Daniel A., Laura M. Betancourt, Nancy L. Brodsky, Hallam Hurt, and Martha J. Farah. 2012. “Neighborhood Disadvantage and Stress Reactivity." Frontiers in Human Neuroscience 6(277): 1-11.

Hanson, Matthew E. B., Steven C. Hunt, Rivka C. Stone, Kent Horvath, Utz Herbig, Alessia Ranciaro, Jibril Hirbo, William Beggs, Alexander P. Reiner, James G. Wilson, Masayuki Kimura, Immaculata De Vivo, Maxine M. Chen, Jeremy D. Kark, Daniel Levy, Thomas Nyambo, Sarah A. Tishkoff, and Abraham Aviv. 2016. "Shorter Telomere Length in Europeans Than in Africans Due to Polygenetic Adaptation." Human Molecular Genetics 25(11): 2324-30.

Harris, Sarah E., Riccardo E. Marioni, Carmen Martin-Ruiz, Alison Pattie, Alan J. Gow, Simon R. Cox, Janie Corley, Thomas von Zglinicki, John M. Starr, and lan J. Deary. 2016. "Longitudinal Telomere Length Shortening and Cognitive and Physical Decline in Later Life: The Lothian Birth Cohorts 1936 and 1921." Mechanisms of Ageing and Development 154 (March): 43-48.

Haycock, Philip C., Emma E. Heydon, Stephen Kaptoge, Adam S. Butterworth, Alex Thompson, and Peter Willeit. 2014. “Leucocyte Telomere Length 
and Risk of Cardiovascular Disease: Systematic Review and Meta-Analysis." British Medical Journal 349 (July 8): g4227.

Hunt, Steven C., Wei Chen, Jeffrey P. Gardner, Masayuki Kimura, Sathanur R. Srinivasan, John H. Eckfeldt, Gerald S. Berenson, and Abraham Aviv. 2008. “Leukocyte Telomeres Are Longer in African Americans Than in Whites: The National Heart, Lung, and Blood Institute Family Heart Study and the Bogalusa Heart Study." Aging Cell 7(4): 451-58.

Jargowsky, Paul A. 1997. Poverty and Place: Ghettos, Barrios, and the American City. New York: Russell Sage Foundation.

Karb, Rebecca A., Michael R. Elliott, Jennifer B. Dowd, and Jeffrey D. Morenoff. 2012.

"Neighborhood-Level Stressors, Social Support, and Diurnal Patterns of Cortisol: The Chicago Community Adult Health Study." Social Science and Medicine 75(6): 1038-47.

King, Katherine, Jennifer Buher Kane, Peter Scarbrough, Cathrine Hoyo, and Susan Murphy. 2016. "Neighborhood and Family Environment of Expectant Mothers May Influence Prenatal Programming of Adult Cancer Risk: Discussion and an Illustrative Biomarker Example." Biodemography and Social Biology 62(1): 87-104.

Kipling, David. 1995. The Telomere. New York: Oxford University Press.

Kitagawa, Evelyn M., and Phillip M. Hauser. 1973. Differential Mortality in the United States: A Study in Socioeconomic Epidemiology. Cambridge, Mass.: Harvard University Press.

Kling, Jeffrey R., Jeffrey B. Liebman, and Lawrence F. Katz. 2007. “Experimental Analysis of Neighborhood Effects." Econometrica 75(1): 83-119.

Ludwig, Jens. 2012. “Guest Editor's Introduction: Special Issue on MTO." Cityscape 14(2): 1-28.

Ludwig, Jens, Lisa Sanbonmatsu, Lisa Gennetian, Emma Adam, Greg J. Duncan, Lawrence F. Katz, Ronald C. Kessler, Jeffrey R. Kling, Stacy Tessler Lindau, Robert C. Whitaker, and Thomas W. McDade. 2011. "Neighborhoods, Obesity and Diabetes: A Randomized Social Experiment." New England Journal of Medicine 365(16): 1509-19.

Lynch, Shannon M., M. K. Peek, Nandita Mitra, Krithika Ravichandran, Charles Branas, Elaine Spangler, Wenting Zhou, Electra D. Paskett, Sarah Gehlert, Cecilia DeGraffinreid, Timothy R. Rebbeck, and Harold Riethman. 2016. “Race, Ethnicity, Psychosocial Factors, and Telomere
Length in a Multicenter Setting." PLoS One 11(1): e0146723. DOI:10.1371/journal.pone.01146723.

Marioni, Riccardo E., Sarah E. Harris, Sonia Shah, Allan F. McRae, Thomas von Zglinicki, Carmen Martin-Ruiz, Naomi R. Wray, Peter M. Visscher, and Ian J. Deary. 2016. “The Epigenetic Clock and Telomere Length are Independently Associated with Chronological Age and Mortality." International Journal of Epidemiology 45(2): 424-34.

Martinez-Ruiz, Carmen M., Jacobijn Gussekloo, Diana van Heemst, Thomas von Zglinicki, and Rudi G. J. Westendorp. 2005. “Telomere Length in White Blood Cells Is Not Associated with Morbidity or Mortality in the Oldest-Old: A Population-Based Study." Aging Cell 4(6): 287-90.

Massey, Douglas S. 1990. "American Apartheid: Segregation and the Making of the Underclass." American Journal of Sociology 95(2): 1153-88.

_ 2013. "Inheritance of Poverty or Inheritance of Place? The Emerging Consensus on Neighborhoods and Stratification." Contemporary Sociology 42(5): 690-97.

Massey, Douglas S., Len Albright, Rebecca Casciano, Elizabeth Derickson, and David Kinsey. 2013. Climbing Mount Laurel: The Struggle for Affordable Housing and Social Mobility in an American Suburb. Princeton, N.J.: Princeton University Press.

Massey, Douglas S., and Susan Clampet-Lundquist. 2008. "Neighborhood Effects on Economic SelfSufficiency: A Reconsideration of the Moving to Opportunity Experiment." American Journal of Sociology 114(1): 107-43.

Massey, Douglas S., and Mitchell E. Eggers. 1992. “A Longitudinal Analysis of Urban Poverty: Blacks in U.S. Metropolitan Areas Between 1970 and 1980." Social Science Research 21(2): 175-203.

Massey, Douglas S., and Mary J. Fischer. 2000. "How Segregation Concentrates Poverty." Ethnic and Racial Studies 23(4): 670-91.

Massey, Douglas S., and Jacob S. Rugh. forthcoming. "Zoning, Affordable Housing, and Segregation in U.S. Metropolitan Areas." In The Fight for Fair Housing: Causes, Consequences and Future Implications of the 1968 Federal Fair Housing Act, edited by Gregory Squires. New York: Taylor and Francis.

Massey, Douglas S., and Jonathan Tannen. 2015. “A Research Note on Trends in Black Hypersegregation." Demography 52(3): 1025-34. 
Mathur, Maya B., Elissa Epel, Shelley Kind, Manisha Desai, Christine G. Parks, Dale P. Sandler, Nayer Khazeni. 2016. "Perceived Stress and Telomere Length: A Systematic Review, Meta-Analysis, and Methodologic Considerations for Advancing the Field." Brain, Behavior, and Immunity 54 (May): 158-69.

Mitchell, Colter, John Hobcraft, Sara S. McLanahan, Susan Rutherford Siegel, Arthur Berg, Jeanne Brooks-Gunne, Irwin Garfinkel, and Daniel Notterman. 2014. "Social Disadvantage, Genetic Sensitivity, and Children's Telomere Length." Proceedings of the National Academy of Sciences 111(16): 5944-49.

Needham, Belinda L., David Rehkopf, Nancy Adler, Steven Gregorich, Jue Lin, Elizabeth H. Blackburn, and Elissa S. Epel. 2015. “Leukocyte Telomere Length and Mortality in the National Health and Nutrition Examination Survey, 1999-2002." Epidemiology 26(4): 528-35.

Orr, Larry, Judith D. Feins, Robin Jacob, Erik Beecroft, Lisa Sanbonmatsu, Lawrence F. Katz, Jeffrey B. Liebman, and Jeffrey R. Kling. 2003. Moving to Opportunity: Interim Impacts Evaluation. Washington: U.S. Department of Housing and Urban Development.

Park, Minjung, Josine E. Verhoeven, Pim Cuijpers, Charles F. Reynolds III, Brenda W. J. H. Penninx. 2015. “Where You Live May Make You Old: The Association Between Perceived Poor Neighborhood Quality and Leukocyte Telomere Length." PLoS One 10(6): e0128460. DOI:10.1371/journal. pone.0128460.

Pettigrew, Thomas. 1979. "Racial Change and Social Policy." Annals of the American Academy of Political and Social Science 441(1): 114-31.

Quillian, Lincoln. 2012. “Segregation and Poverty Concentration: The Role of Three Segregations." American Sociological Review 77(3): 354-79.

Rothwell, Jonathan, and Douglas S. Massey. 2014.

“Geographic Effects on Intergenerational Income Mobility." Economic Geography 91(1): 83-106.

Rubinowitz, Leonard S., and James E. Rosenbaum. 2000. Crossing the Class and Color Lines: From Public Housing to White Suburbia. Chicago: University of Chicago Press.

Rudolph, Kara E., Wand Gary S., Elizabeth A. Stuart, Thomas A. Glass, Andrea H. Marques, Roman Duncko, and Kathleen R. Merikangas. 2014. “The Association Between Cortisol and Neighborhood Disadvantage in a U.S. Population-Based Sam- ple of Adolescents." Health and Place 25(1): 6877.

Sampson, Robert J. 2012. Great American City: Chicago and the Enduring Neighborhood Effect. Chicago: University of Chicago Press.

Sampson, Robert J., Jeffrey Morenoff and T. GannonRowley. 2002. “Assessing Neighborhood Effects: Social Processes and New Directions in Research." Annual Review of Sociology 28(1): 44378.

Sanbonmatsu, Lisa, Jens Ludwig, Lawrence F. Katz, Lisa A. Gennetian, Greg J. Duncan, Ronald C. Kessler, Emma Adam, Thomas W. McDade, Stacy Tessler Lindau, Matthew Sciandra Fanghua Yang, Ijun Lai, William Congdon, Joe Amick, Ryan Gillette, Michael A. Zabek, Jordan Marvakov, Sabrina Yusuf, and Nicholas A. Potter. 2011. Moving to Opportunity for Fair Housing Demonstration Program: Final Impacts Evaluation. Washington: U.S. Department of Housing and Urban Development.

Sanders, Jason L., and Anne B. Newman. 2013. “Telomere Length in Epidemiology: A Biomarker of Aging, Age-Related Disease, Both, or Neither?" Epidemiological Reviews 35(1): 112-31.

Sapolsky, Robert M. 2004. “Organismal Stress and Telomeric Aging: An Unexpected Connection." Proceedings of the National Academy of Sciences 101(50): 17323-24.

Schutte, Nicola S., and John M. Malouff. 2014. “The Relationship Between Perceived Stress and Telomere Length: A Meta-Analysis." Stress and Health 32(4): 313-19.

Shalev, Idan, Terrie E. Moffitt, Karen Sugden, Brittany Williams, Renate M. Houts, Andrea Danese, Jonathan Mill, Louise Aresneault, and Avshalom Caspi. 2013. “Exposure to Violence During Childhood Is Associated with Telomere Erosion from 5 to 10 Years of Age: A Longitudinal Study." Molecular Psychiatry 18(5): 576-681.

Sharkey, Patrick. 2013. Stuck in Place: Urban Neighborhoods and the End of Progress toward Racial Equality. Chicago: University of Chicago Press.

Theall, Katherine P., Zoë H. Brett, Elizabeth A. Shirtcliff, Erin C. Dunn, and Stacy S. Drury. 2013. Neighborhood Disorder and Telomeres: Connecting Children's Exposure to Community Level Stress and Cellular Response." Social Science and Medicine 85(1): 50-58.

Walsemann, Katrina M., Gilbert C. Gee, and Arline Geronimus. 2009. “Ethnic Differences in Trajec- 
tories of Depressive Symptoms." Journal of Health and Social Behavior 50(1): 82-98.

Wilhide, Eli. 2014. Understanding Telomeres: The

Science of Aging Well. Seattle, Wash.: Amazon

Digital Services.

Willeit, Peter, Johann Willeit, and Agnes Mayr. 2010.

"Telomere Length and Risk of Incident Cancer and Cancer Mortality." Journal of the American Medical Association 304(1): 69-75.

Wilson, William J. 1987. The Truly Disadvantaged:

The Inner City, the Underclass, and Public Policy.

Chicago: University of Chicago Press.

Wodtke, Geoffrey T., David J. Harding, and Felix Elw- ert. 2011. “Neighborhood Effects in Temporal Perspective: The Impact of Long-Term Exposure to Concentrated Disadvantage on High School Graduation." American Sociological Review 76(5): 713-36.

- 2016. "Neighborhood Effect Heterogeneity by Family Income and Developmental Period."

American Journal of Sociology 121(4): 1168-222.

Yu, Ruby, Nelson Tang, Jason Leung, and Jean Woo. 2015. “Telomere Length Is Not Associated with Frailty in Older Chinese Elderly: Cross-Sectional and Longitudinal Analysis." Mechanisms of Ageing and Development 152 (December): 74-79. 